\title{
On the Internal Argument(s) of Unaccusative [Verb+Preposition] Structures
}

\author{
Concha Castillo \\ University of Málaga \\ ccastillo@uma.es
}

\begin{abstract}
In this paper I use the feature [+/-animate] to distinguish unaccusative [verb+preposition] structures where the verb projects the internal argument from structures where the preposition projects the internal argument. On the proposed approach, which aims to be a refinement on the original work by Hoekstra (1988), the preposition selects for the internal argument whenever the latter is [-animate]. The analysis is supported by the observation that unaccusative prepositional structures are typically [-animate], by contrast with their non-prepositional counterparts, and by a principled analysis of the differences existing between sequences with march-type verbs vs. sequences with verbs like whistle or eat. By contrast with current works in the literature, the preposition is argued to project two Spec positions in eat-type sequences, and a $p \mathrm{P}$-shell configuration is proposed to match the derivation of unaccusative [verb+preposition] structures that feature one or two arguments internal to the prepositional projection.
\end{abstract}

\section{Introduction}

This paper argues that an analysis of the animacy property can be used to construct an approach to unaccusative [verb+preposition] structures - that is, [verb+preposition] structures lacking an external argument - that distinguishes whether it is the verb or otherwise the preposition that selects for the argument in surface subject position, that is the internal argument. 
It is widely known that an important part of the generative literature has focused in the last years on the capacity of prepositions to project subjects of their own, a trend that is inaugurated by the influential work within GB theory of Hoekstra (1984, 1988, 1992, 1999), and that is later built upon by the seminal approach to argument structure of Hale and Keyser (1993, 2002), which treats prepositions as predicates with the capacity to project specifiers. Drawing on relevant generalisations previously made in Stowell (1981) and Simpson (1983), and basing upon the notion of result, Hoekstra (1984, 1988) comes to analyse [verb+preposition] structures like (1) as ones where the verb takes a Small Clause (SC) complement whose predicate is the preposition. For its part, the minimalist $v$-P approach of Hale and Keyser (2002) must be regarded as a revolutionary preposition-based account of the argument structure of a large part of the English lexicon. The authors' approach hinges in an important way on the analysis of transitive prepositional verb phrases like [put the books on the shelf] as structures where the direct object DP (the books) is projected in a Spec position of the preposition.

(1) a. The soldiers ${ }_{i}$ marched $\left[t_{i}\right.$ to the tents]

b. $\mathrm{John}_{\mathrm{i}}$ flew [ $\mathrm{t}_{\mathrm{i}}$ to a British airport $]$

In the wake of Hoekstra, and using mainly perfective auxiliary selection as a diagnostic test, various works in the literature emphasise the unaccusative status of verbs like march or fly whenever these combine with a prepositional projection, that is with a PP constituent. By contrast, the verbs in question behave as unergative (or agentive) in case no such projection occurs.

Now, though there is generalised consensus on the unaccusative status of (1), in a (minimalist) framework where verb phrases have the structure of $v$ P-shells generally speaking, and therefore enough space for more than one internal position, it is not entirely clear whether the relevant internal object in (1) (that is, the entity carrying out the movement: the soldiers or John) is an argument of the verb, or an argument of the preposition. In a relevant way, the occurrence of a prepositional projection appears to be connected with the feature [+/-animate], since the vast majority of types that can be distinguished within the set of unaccusative [verb+preposition] structures according to verb meaning feature a [-animate] subject argument, whereas the majority of unaccusative non-prepositional structures allow for either a [+animate] or a [-animate] subject argument. This is actually quite logical, given the general assumption that the animacy property is typically imposed by a predicate upon its subject. Further, in a very important way, several works in the literature have established a correlation between the prepositional vs. non-prepositional status of a given sequence and the [+/-animate] of its subject argument (see Levin and Rappaport Hovav (1995), Folli and Harley (2005, 2006), Harley (2007), Zubizarreta and Oh (2007)).

In this paper I aim to clarify the dilemma regarding (1) above, that is whether the internal object is projected by the verb or by the preposition, through an exploration of the connections existing between the three aforementioned oppositions: the unaccusative vs. unergative (or agentive) value of the construction on the one hand, its 
prepositional vs. non-prepositional status on the other, and the feature [+animate] vs. [animate] of the internal argument on the other. It is expected that the analysis of (1) can be applied to the overall set of unaccusative [verb+preposition] constructions generally speaking, whether these denote result or not. In an important way, I aim to clarify or criticise certain aspects discussed in some of the above-mentioned works in connection with the animacy property of surface subjects. Further, I must emphasise that I do not deal in this paper particularly with transitive preposition structures of the type [put the books on the shelf], and that likewise the host of transitive prepositional types that participate in so-called argument structure alternations are out of the scope of the present discussion (see Section 1.1 below).

The paper is organised as follows. In $1.1 \mathrm{I}$ describe the motivation behind the work of Hoekstra and later Hale and Keyser for treating prepositions as predicates projecting subject positions, and in 1.2 I justify an analysis of unaccusative [verb+prepositions] that is based on the animacy property of the subject argument. I propose to defend a taxonomy of non-prepositional structures that acknowledges the feature [+/-animate] of the surface subject, and in Section 2 I establish a comparison between such a taxonomy of non-prepositional structures and the corresponding taxonomy in the prepositional domain. 2.1 and 2.2 arguably constitute the core of the discussion since here are analysed the specific constructions that appear to provide the clue as to the head selecting for the subject in unaccusative [verb+preposition] structures: whether such a head is the verb or the preposition. Finally, in Section 3, I propose a $p \mathrm{P}$-shell structure as the configuration-type that can satisfy the requirements of the argument structure of the constructions under analysis, that is of unaccusative [verb+preposition] constructions.

Some observations are in order relative to the meaning and scope of the term [verb+preposition] structure or construction as used in the paper. First, this term is employed in a neutral sense, by which is meant a configuration where the verb combines with a PP-complement, without any implication as to the compositional or otherwise idiomatic meaning of the structure, or as to the status of the latter as a lexical unit. Secondly, the PP constituents that are relevant for the discussion are ones headed either by an ordinary transitive preposition, or by a particle. The present discussion assumes that particles belong, together with ordinary or transitive prepositions, to the category preposition. It is well known that particles have traditionally been argued to differ from ordinary prepositions in their potential mobility (hence the name particle shift) and in that they do not check or license Case-features. However, the set of particles is largely homonymic with that of ordinary prepositions and, as standardly assumed, particles accept the same range of modifiers as prepositions (for instance, right or straight), which would seem to justify treating both of them as elements of the same category P (see a classical work like Emonds 1972). Further, in an important way, Kayne (1985) applies the SC approach to resultative structures introduced by Stowell (1981) and Hoekstra (1984) to the specific case of verb-particle constructions, and analyses these as constructions where a core subject-predicate relation holds between the surface object and the particle (John looked [sC[the information][up]]. ${ }^{1}$ It must be 
emphasised that this paper does not deal with key issues in the domain of verb-particle constructions such as the availability of the alternative orders object-particle/particleobject, or the Case-checking phenomena related to these: a brief reference to these phenomena can be found at the end of Section 3 of the paper.

\subsection{Background to a V-SC approach to [verb+preposition] structures}

Hoekstra (1988) uses the notion of Small Clause (SC), which could be roughly characterised as the thematic relation between a subject and a predicate without the mediation of Inflection, in order to investigate the claim initially made explicit by Stowell (1981) that APs and PPs can possibly have subjects. Hoekstra's analysis relies in a significant way on the idea of result. Effectively, the author establishes a paradigm of resultative structures where a postverbal NP (or DP) appears to receive a theta-role not from the matrix verb but instead from an AP or PP predicate that follows, though it obligatorily receives accusative Case in ECM fashion from the matrix verb itself. The material in brackets in (2) below, which represents a relevant portion of the structural types investigated by the author, is analysed as an SC complement whose predicate denotes some kind of effect or result as suffered by a given entity because of the causative meaning of the matrix verb. The DP within the first pair of brackets plays the role of subject of the SC, and the AP/PP is of course identified as the predicate itself. Leaving aside structures with an AP predicate like (2a), which fall out of the scope of this discussion, the type of PP predicate that can be found in Hoekstra's paradigm is specifically headed by a directional preposition (whether an ordinary transitive preposition, or a so-called particle): this is because the meaning of direction of the preposition happens to identify the end position of the moving entity as resulting from the movement itself, whence the connection between the meaning of result of the overall structure and the directional meaning of the preposition. ${ }^{2}$

(2) a. He laughed [[himself] [sick]]

b. We talked [[her] [out of her crazy schemes]]

c. He washed [[the soap] [out of his eyes]]

d. They danced [[their days] [away]]

e. He shaved [[his hair] [off]] (Hoekstra 1988: 115, 116)

A core aspect of Hoekstra (1988), which is to be found originally in Hoekstra (1984) and which is further developed in Hoekstra (1999), is that the SC analysis that the author implements on dynamic or activity verbs (whether these are transitive as in $(2 \mathrm{c}$, e) or unergative (as in $(2 a, b, d)$ is applied arguably successfully to configurations in Dutch where the matrix predicate is a verb of movement. Incidentally, in a trivial way, the above-mentioned meaning of direction expressed by the preposition fits perfectly with the meaning of motion or movement of such verbs.

Hoekstra uses auxiliary selection or also prenominal modification phenomena as diagnostic tests in order to distinguish the unergative status of a structure like ( $3 \mathrm{a})$ from 
the unaccusative status of (3b), and thus comes to lend wide support to the core claim made by Simpson (1983) according to which all resultative constructions on a general basis are object related.

(3) a. dat Jan loopt / heeft gelopen that John walks has walked

b. dat Jan naar Groningen loopt / is gelopen that John to Groningen walks / is walked (Hoekstra 1988: 134)

In a parallel fashion to the structures in (2), the author argues that it is not the verbal predicate that theta-marks or, the same, imposes its own selectional restrictions upon the NP/DP immediately preceding them, but the PP that is analysed as the predicate of a $\mathrm{SC}$ constituent, as shown in (4). The original position or function of the cited NP/DP is that of subject of the SC.

(4) a. dat [ ${ }_{\mathrm{VP}} \mathrm{J}$ an heeft gelopen]

b. dat $\left[{ }_{\mathrm{VP}} \mathrm{Jan}_{\mathrm{i}}\left[\mathrm{sC}_{\mathrm{i}}\right.\right.$ naar Groningen] is gelopen]

Now, irrespective of the resultative interpretation underlying Hoekstra's proposal, the SC analysis that Hoekstra motivates for unaccusative constructions is crucially biased by the need to argue that the PP element occupies a complement position within the verb phrase and not the position of an adjunct: since the verb phrase prior to the development of the $\nu \mathrm{P}$-shell architecture contains just one complement or object position (namely, the complement or object position of $\mathrm{V}$ ), then the author is forced to argue that the internal DP argument is a constituent within the PP itself. The treediagram in (5a) below represents the relevant verb phrase.

With the advent in syntactic theory of the little $v$ projection (Chomsky 1995, 2000, 2001), however, two internal positions become available within the verb phrase (aside of course from the position of the external argument or logical subject, which corresponds to $\mathrm{Spec}, \mathrm{V}$ in the former approach, and to $\mathrm{Spec}, v$ in the new $v \mathrm{P}$ architecture): these are $\mathrm{Spec}, \mathrm{V}$ and the complement or object position of V (V,DP). See (5b) for the relevant $v \mathrm{P}$-shell configuration.

(5) a.

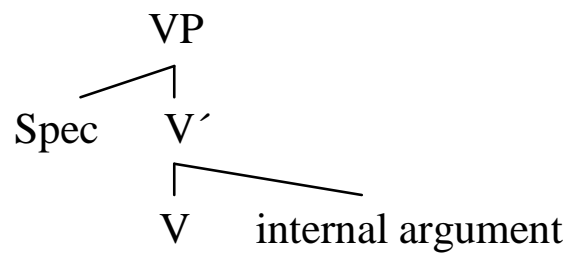

Figure 1 
(5) b.

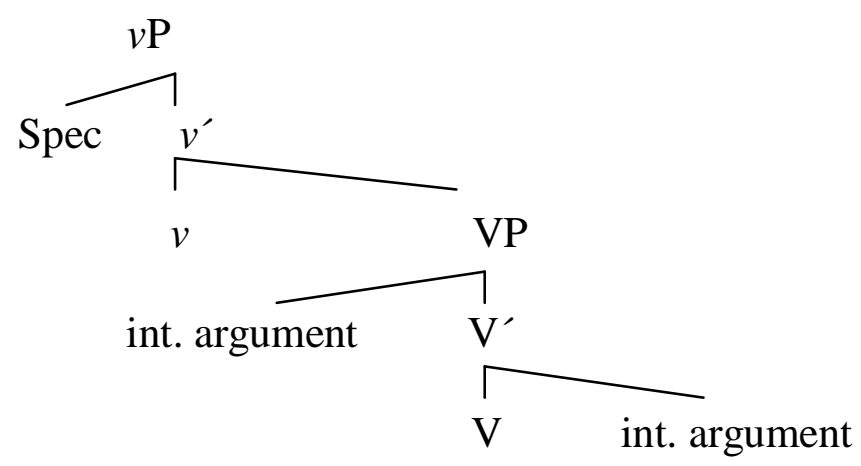

As observed in the Introduction, the trigger of the present discussion is the necessity to determine the precise position of merge of the internal DP in prepositional structures like (1) or, likewise (3) above, an issue that appears to be neglected in current minimalist literature. In other words, though the internal status of the non-agentive DP in the above structures is granted given that it does not occupy Spec, $v$ (which is the position of the logical subject or agent), it is necessary to clarify which of the two internal positions in (5b) it does occupy, whether Spec, V or V,DP, and also it is necessary to ellucidate whether prepositional structures generally speaking differ on this point.

Now, the SC analysis of Hoekstra apppears to have been a major source of inspiration for the work of Hale and Keyser $(1993,2002)$ in the domain of lexical argument structure, or for the influential study of Levin and Rappaport Hovav (1995). To these works could be added others like Rappaport Hovav and Levin (2001), or Broccias (2003), or also, the relevant work of den Dikken $(1995,2006,2009)$ in the field of the syntax and semantics of directional prepositions (and/or particles) both in English and in Dutch. ${ }^{3}$

Particularly, Hale and Keyser (2002) must be considered a seminal approach to the argument structure of both verbal and prepositional predicates in English. Roughly speaking, the authors start with the analysis of transitive prepositional structures like (6) as ones where the preposition and not the verb supplies the locatum object the books, in addition to the location object the shelf (see (6b)), and then extend the approach to a considerable number of structures variously involving transitive/intransitive alternations, as in $(7 \mathrm{a}, \mathrm{b})$, or also prepositional/non-prepositional alternations, as in the classical dative construction in $(7 \mathrm{c})$, to cite a few.

(6) a. He put the books on the shelf

b. [vput [pthe books [pon [Dpthe shelf]]]]

(7) a. The kids splashed mud on the wall / Mud splashed on the wall

b. The kids smeared mud on the wall / *Mud smeared on the wall

c. She gave a book to her daughter / She gave her daughter a book

Hale and Keyser motivate an analysis of the argument structure of a large part of the English lexicon on which prepositions - either in an overt or a covert form - have the 
capacity to project a specifier, in addition to a complement. As in Hoekstra's approach, the direct object DP in e.g. (6) is considered to be an argument of the preposition, though Hale and Keyser's approach does not rely on the idea of result, but on the more general capacity or property of prepositions to put in connection two entities, which arguably correlates with their structural capacity to project both a complement and a specifier. Nonetheless, it is the locative meaning of prepositions that is ultimately at the base of both accounts: as mentioned earlier in the Section, Hoekstra (1988) focuses on structures with prepositions meaning direction (which is a locative meaning) since the end position of the entity moving once the movement has been realised is seen in a logical way as a resulting state; on the other hand, though Hale and Keyser (2002:8) observe that the relation that prepositions specify between two entities is of a locative type, or also temporal, or other, it can be safely assumed that prepositions are all inherently or originally locative elements, though their locative meaning can be or has actually been subject to metaphorical extensions in manifold cases. ${ }^{4}$

By contrast with Hoekstra's approach, the present analysis to prepositional structures does not deal with the idea of result. More importantly, by contrast with Hale and Keyser's account, the present analysis is motivated by the hypothesis or idea that not all prepositions (in unaccusative [verb+preposition] structures) have the capacity to project a specifier. Effectively, Hale and Keyser (2002) deal not only with transitive structures like those in (6)-(7) above, but also with unaccusative structures like (8): in line with the analysis entertained for other structural types, the authors argue that the argument in surface subject position is contributed by the preposition, whether the latter is present or not.

\section{(8) Many guests arrived (at the party)}

Now, the present approach does not endorse the idea of the availability of covert or tacit prepositions: for one thing, the discussion is centred around the contrasts between prepositional structures on the one hand, and non-prepositional structures on the other. On the present approach, an argument like e.g. many guests in (8) above is thus an argument of the verb whenever no preposition is overtly present in the structure. The hypothesis guiding the present analysis is rather the possibility that the feature $[+/-$ animate] could actually sanction an internal argument as an argument of the verb or as an argument of the preposition, the ultimate goal being to provide a principled characterisation of unaccusative [verb+preposition] structures as based on these facts. Thus, the question to pose on the present approach as regards the prepositional variant in (8) is whether it is the verb or the preposition that selects for the internal argument (many guests). The question will be tackled in Section 2.2.1 of the paper.

It must be clarified that prepositions are assumed here, exactly as in Hale and Keyser (2002), not to be able to project an external argument or logical subject: that is, the DP arguments he, the kids, or she in (6)-(7) can only be projected by the verb (in the corresponding Spec, $v$ position). For the scope of the paper to be unaccusative [verb+preposition] structures means that constructions like (6)-(7) above, or indeed 
structures like (2b-e) above, are left out of the discussion, irrespective of the fact that such structures arguably feature an internal argument. The present paper thus focuses on unaccusative movement structures like (1) above, and then tries to extend the analysis to remaining [verb+preposition] structures where the verb projects no agent or external argument. Nonetheless, as noted in the Introduction, the opposition unaccusative/unergative is a decisive part of the discussion. A characterisation of the minimal contrasts existing between unaccusative structures on the one hand and agentive or unergative ones on the other is provided in the Sections that follow.

\subsection{Agentive vs. unaccussative non-prepositional structures: the animacy property}

Animacy cannot be considered either a sufficient or a necessary property for the agentive/unaccusative distinction since it is possible to find both [+animate] and [animate] arguments in the subject and/or object positions of both structural types generally speaking. In effect, animacy does not figure explicity in the characterisation of agentivity proposed in the influential work of Dowty (1991), ${ }^{5}$ or in later developments like Davis and Koenig (2000) or Koenig and Davis (2001), and neither is it regarded as a criterial property in the comprehensive revision of Levin and Rappaport Hovav (2005). A comparison between [animacy] on the one hand and [cause] or [sentience] on the other, which are two prominent features of agentivity typically acknowledged in the cited literature, shows that [animacy] lacks the explanatory power of these features: for one thing, [sentience] entails or is more than [animacy], which makes [animacy] itself redundant and, on the other hand, a [cause] or [causative] argument can be either [+animate] or [-animate]. See 1.2.2 for a more detailed characterisation of the features [cause] or [causative], and [sentience].

However, even a coarse-grained typology of agentive vs. unaccusative structures reveals that some classes of verb phrases are actually sensitive to the feature [+/animate] or, the same, that some predicates impose animacy requirements on the arguments that they select. More specifically, several works in the current literature have put the emphasis on significant contrasts between prepositional structures on the one hand and non-prepositional structures on the other that so relate to the feature [+/animate]: see Folli and Harley (2005, 2006), Harley (2007), Zubizarreta and Oh (2007) or also, prior to these, Levin and Rappaport Hovav (1995). The present paper aims to analyse whether such contrasts could possibly reveal if it is the verb or otherwise the preposition that selects for the argument in subject position of unaccusative [verb+preposition] structures, or the same, if such contrasts support or contradict the SC analysis originally proposed in Hoekstra $(1984,1988)$ according to which the subject argument is an argument of the preposition. In order to achieve this, I first try to acknowledge the animacy properties of the minimal types of non-prepositional verb phrases that can arguably be distinguished according to verb meaning, for which I make use of the classification provided in Levin (1993), though in a very loose or general way. 
Insisting then that the aim is not to provide a fine-grained taxonomy of nonprepositional verb-types, but a minimal explanatory taxonomy that can possibly be contrasted in a relevant way with [verb+preposition] structures, (9) below is claimed to be such a taxonomy. It must be highlighted that the specification [+/-animate] is relative to the argument in the position of surface subject, that is the argument that eventually raises from some position within the verb phrase to Spec,T. A description of each class is in order in 1.2.1 and 1.2.2 below.

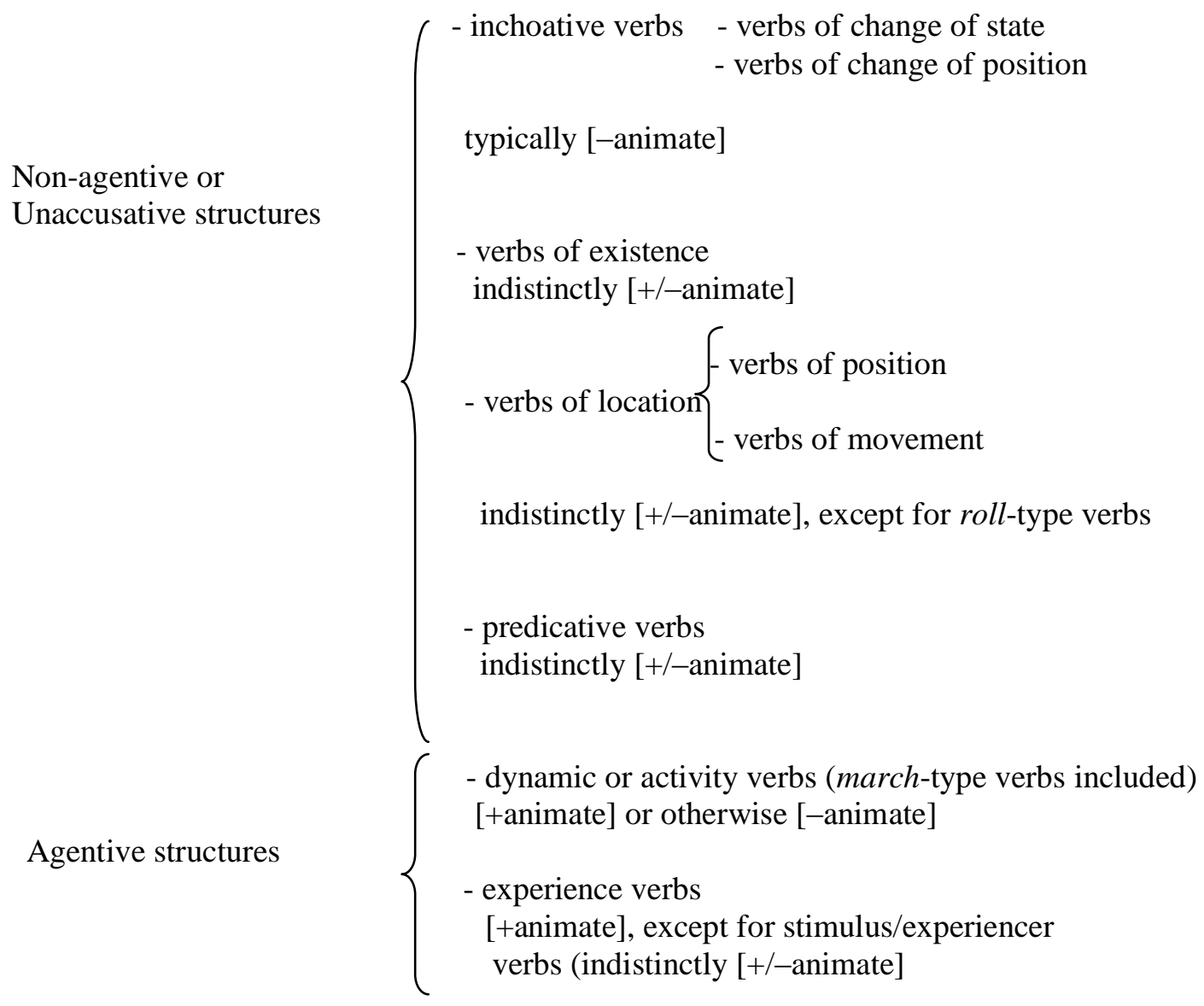

Figure 3

\subsubsection{The non-agentive or unaccusative types}

Non-agentive or unaccusative (non-prepositional) structures are of course ones whose surface subject is an internal argument, hence liable to be characterised in terms of object affectedness. Anderson (1977) introduces a three-fold typology of [+affected] objects, which is later basically endorsed by Dowty (1991), and which covers (i) altered or modified objects, (ii) displaced objects, and (iii) effected objects. Assuming the concept of [+affected] object proposed by Anderson (1977), both inchoative verbs and verbs of movement within the unaccusative set arguably feature a [+affected] object, since the former denote the alteration of the state or position of some object (10a) and, 
for their part, verbs of movement in a trivial way describe the displacement of an entity $(10 \mathrm{~d}-\mathrm{e}){ }^{6}$

(10) a. The door closed

b. There appeared a stranger on the corner / There appeared a ship on the horizon

c. John was lying under the bed / The presents were lying under the bed

d. The guests have arrived / The letter has arrived

e. The ball rolled

f. His colleagues are honest people / The white dress is so beautiful

Centring now upon the aspect that is most interesting for the purposes of the present discussion, the majority of verb-classes or verb-types within the unaccusative set can be said to indistinctly select for a [+animate] or a [-animate] argument: note (10) above, where a situation of existence (10b), of position or movement $(10 \mathrm{c}, \mathrm{d}, \mathrm{e})$, or of predication (10f) is denoted of both [+animate] and [-animate] entities. There appear to be two exceptions to this general characterisation. On the one hand, the class of inchoative verbs typically demands a [-animate] argument, as in (10a), though it must be granted that a case like (11a) is potentially analysable not only as a movement sequence but also as an inchoative sequence.

(11) a. The child moved

b. He moved the child (agentive or causative counterpart)

On the other hand, the class of so-called roll-type verbs, or also bounce-type verbs, are characterised in works like Levin (1993) or Levin and Rappaport Hovav (1995) as typically describing the movement or displacement of a [-animate] entity (see (10e) above). Incidentally, whether a sequence like (12) is actually much less natural than (10e) is not so important for the purposes of the present discussion: what matters is the way in which roll-type verbs contrast with march-type verbs as regards the occurrence of a PP constituent. The relevant connection is introduced in 1.2.2 below.

\section{(12) ??John rolled}

\subsubsection{The agentive types}

Turning now to the set of agentive (non-prepositional) structures in taxonomy (9) above, this includes: the class of dynamic or activity verbs, which is closely connected with the features [cause] or [causative] on the one hand, and [movement] on the other, and the class of experience verbs, which entails the feature [sentience].

Now, the class of non-prepositional dynamic or activity verbs is crucial for the present discussion, since it contains in itself certain classes of verbs that contrast in a relevant way with prepositional verbs (to be described in Section 2 below). Before 
dealing with the animacy property, a brief characterisation of the features [cause], [movement], and [sentience] is in order.

The class of dynamic or activity verbs comprises manifold verb-types or verbclasses (see Levin 1993), all of which take an agent argument, that is a type of entity that does something or is actively involved in some action, and that, as generally assumed in minimalist syntax, is merged in the Spec of little $v$. Agents whose action affects another entity (see reference to Anderson (1977) in 1.2.1 above), which is incidentally a logical or internal object, are identified with the feature [cause] or [causative]: such is the case with all the subject arguments in (13)-(16), which are described below in this Section in connection with the feature [+/-animate]. By contrast with these, the agent in a sequence like (17) is not [cause] or [causative], since the object the book cannot be considered as being altered or modified, displaced, or as an effected entity.

(13) a. John hit the ball

b. Mary opened the door

c. John will sink the ship

(14) a. The rain hit the window

b. The storm might destroy the crops

c. The wind has opened the door

(15) a. An arrow hit the window

b. This key will open the door

(16) a. A construction fault sank the ship

b. The pressure will crack the window

(17) John read the book

On a par with [cause] or [causative], agents can be associated with the feature [movement], as in (18), or with the feature [sentience], which takes us to the class of verbs of experience illustrated in (19). These include, as is widely known, verbs of perception (19a), cognition (19b), or psychological verbs (19c), and select for a subject argument that is not as agentive as those of activity verbs, since it is not involved in a physical activity proper, or an activity that is directly measurable or observable. ${ }^{7}$

(18) a. The soldiers marched

b. They are running today

c. John is flying next week

(19) a. John heard the noise

b. John thinks otherwise

c. John likes Mary / Mary hates milk

Now, the inclusion of movement verbs like march, run, or fly within the agentive class (note (18) above) leads us to the seminal contrast acknowledged in Levin and Rappaport Hovav (1995) between these verbs and verbs of the roll-type (see (10e) 
above). Effectively, tests like auxiliary selection in manifold languages give evidence that verbs like run, march, fly, or jog must be characterised as agentive, that is as verbs selecting for an agent subject, whereas verbs like roll or bounce are instead unaccusative, and select for logical objects or, the same, internal arguments. Nonetheless, it is the relation that each of these two classes of verbs maintain with potential PP constituents that is at the core of the proposal in this paper. Such relation is analysed in Section 2 below.

The aspect to tackle right now concerns the [+/-animate] characterisation of the class of activity verbs - whether these are characterised as [cause], [movement], or none of these - and also of the class of experience verbs. Very briefly, [sentience] entails [+animate], which trivially means that experience verbs typically select for a [+animate] entity as subject (see (19) above). A subclass within the experience set, namely the well-known class of stimulus-experiencer psychological predicates, can nevertheless indistinctly select for a [+animate] or a [-animate] stimulus in subject position:

(20) a. John annoyed Mary / The noise annoyed Mary

b. The gardener pleases John / Music pleases John

As for the animacy demands of the class of activity or dynamic verbs, these predicates contrast in a significant way with the verbs in the unaccusative class described in 1.2.1 above. Effectively, whereas the (vast) majority of unaccusative verbs can select alternatively or indistinctly for a [+animate] or a [-animate] surface subject, verbs within the dynamic or activity class are divided between those that are capable of taking a [+animate] argument, and those that are not (see taxonomy (9) above).

Now, I would like to argue that the set of [-animate] arguments that can appear in the subject position of activity verbs includes: natural forces, as in (14) above, instruments, as in (15), and organic causes, as in (16), and further that the relevant verbs typically denote a situation of force or violence, or one where the position of an object is changed or modified. ${ }^{8}$ As shown in (13)-(16) above, verbs like hit, destroy, sink, or open can select either for a [+animate] or a [-animate] subject agent. By contrast with these, there are manifold verb classes that are typically used to denote an activity carried out exclusively by a [+animate] entity, or even a [+human] entity. (21) and (22) below are verb-type names borrowed from Levin (1993) which serve as illustrations of these two major types of activity verbs: those in (21) can take a natural force, instrument, or organic cause as subject, in addition to a [+animate] argument, as described above, ${ }^{9}$ whereas those in (22) are restricted to co-occurring with [+animate] subject entities. Note, incidentally, that (22) includes march-type or, the same, run-type verbs, which, as standardly assumed, differ from (unaccusative) roll-type verbs as regards animacy.

(21) verbs of removing, verbs of throwing, verbs of contact by impact, poke verbs, verbs of cutting, verbs of combining and attaching, verbs of separating and disassembling, destroy verbs, verbs of change of state,... 
(22) verbs of searching, social interaction, ingesting, verbs involving the body, verbs of grooming and bodily care, verbs of sound emission, transcribe verbs,... verbs of motion: manner of motion verbs of the run-type, verbs that are vehicle names, waltz verbs,...

The aspects to emphasise from the above are the following. [-animate] subject arguments of activity verbs are necessarily [cause] or [causative], since the verbs selecting for these subjects denote force or change of position, and these are meanings typically covered by the definition of affected object (see above in the Section). By contrast, [+animate] subject arguments of activity verbs can be [cause] or [causative], or not. Instances of the former are: the verbs in (13), (21), and some verbs in (22) such as verbs of ingesting (eat, chew, nibble, devour,...), or verbs of grooming and bodily care (shave, wash, brush), or causative verbs of motion (march, skate, waltz,...). Instances of the latter, that is of [+animate] subject arguments that fail to be [cause] or [causative] are: (17) above, or also various verbs in (22), such as some verbs of searching like track, or smell, or some verbs of the transcribe group like photocopy or photograph. These random illustrations do not in any way contradict the standard assumptions expressed at the beginning of 1.2 above regarding the more determining role of [cause] or [causative] over [animacy] as such agentivity feature, nor do (21) or (22) pretend to be comprehensive of the typology provided in Levin (1993). Rather, the aim is to emphasise the fact that, despite animacy being less relevant than [cause] or [causative] in the ranking of agentivity, it is independent from [cause] or [causative] in the sense that it is possible for a [+animate] subject argument of an agentive verb not to be [cause] or [causative].

Before putting an end to this Section, I would like to comment on two aspects relative to the meaning [+/-animate] that will prove relevant for the discussion below in the paper. One is that all predicates generally speaking have the potential to be used in a figurative or metaphorical sense, as in (23) below. This use, however, must be carefully distinguished from the genuine non-metaphorical meaning of a verb that belongs to list (22) but that takes a [-animate] subject argument when co-occurring with a prepositional projection (see Section 2.2 below).

\section{(23) The wind combed his hair (metaphorical meaning)}

The other comment to make is that certain [-animate] entities can be straightforwardly assimilated to a true agentive figure, a property that Bresnan (1994) explains in terms of teleological capability. Thus, the structure in (24), with the plane instead of John in subject position, is understood on the present approach in exactly the same way as (18c) above. The teleological capacity of certain objects will be mentioned again in 2.2.1.

(24) The plane is flying next week 


\section{Agentive vs. unaccussative [verb+preposition] structures: the animacy property}

The aspect of [verb+preposition] structures that is the trigger of the present discussion is the existence of verbs of movement like march or fly whose status as unergative (or agentive) vs. unaccusative depends in a crucial way on the occurrence of a PP, a distinction originally acknowledged by Hoekstra. Effectively, in the wake of Hoekstra (1984, 1988), works like e.g. Hoekstra and Mulder (1990) or Levin and Rappaport Hovav (1995) entertain an analysis of march-type verbs where these are characterised as unaccusatives (that is, as verbs lacking an external argument) just in case they combine with a PP constituent, whereas they are analysed as agentive or unergative (that is, as verbs projecting an external argument) if they select for no PP constituent. A reliable test to use in languages like German or Italian is the choice of the perfective auxiliary be vs. perfective have (see 1.1 above and the Dutch illustrations in (3)).

A sequence like (25a), where the DP the soldiers is an agent proper, belongs within the dynamic or activity set of the agentive class in taxonomy (9) above, whereas the DP the soldiers in (26a) (former (1a)) is a theme or logical object in a locative structure within the non-agentive or unaccusative class of the taxonomy to be introduced in this Section. Instead of theme or logical object, though, I should prefer the term subject of motion for the reason specified immediately below.

(25) a. The soldiers marched

b. [TP [ [ ${ }_{v \mathrm{P}}$ the soldiers [marched]]]

(26) a. The soldiers marched to the tents (=(1a)) (unaccusative)

b. [ ${ }_{\mathrm{TP}} \_\left[{ }_{v \mathrm{P}} \text { marched [the soldiers to the tents]]] }\right.$

(unergative or agentive)

(27) a.

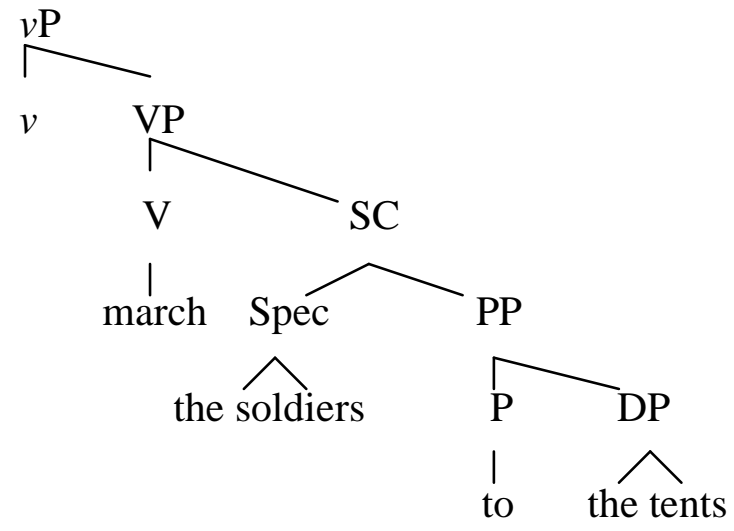

Figure 4

Now, as observed in 1.1 above, the structure in (26b) is vague in a significant way, it being necessary to determine whether an argument like the soldiers merges initially in the derivation as the subject of an SC constituent with the PP to the tents as a predicate, or whether the soldiers merges in Spec,V: see (27a) above vs. (27b) below. Incidentally, it is the location of the DP in the Specifier position of $\mathrm{V}$ rather than in the object or complement position of $\mathrm{V}$ in (27a) that appears to justify its treatment as a subject of 
motion, rather than simply a theme or logical object, since Spec nodes can arguably be related to a broad notion of subject on a general basis.

(27) b.

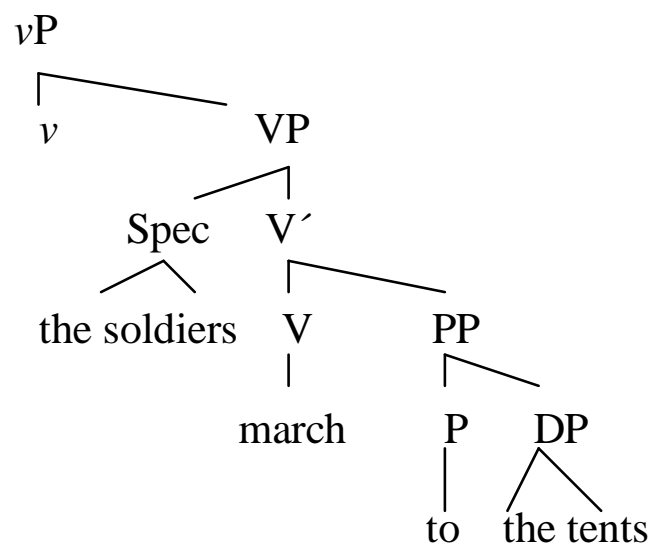

Figure 5

It was noted in 1.1 above that Hoekstra $(1984,1988)$ was arguably forced to claim that the subject of motion in a structure like (26a) is part of the SC constituent projected by the preposition, since the type of verb phrase architecture that was available at the moment contained just one internal position (the one occupied in this case by the SC), the Spec of $\mathrm{V}$ corresponding to the position of the external argument. The development of the $v \mathrm{P}$-shell mechanism in minimalist syntax makes it possible to count on two positions internal to the verb phrase - Spec of $\mathrm{V}$ on the one hand, and the complement position of $\mathrm{V}$ itself on the other - since the external argument is arguably projected in a Spec of little $v$.

The goal of the present Section is to decide which of the two options is the proper one for march-type verbs (whether (27a) or (27b)) and, basing on this, to provide an explanatory account of all [verb+preposition] structures in the unaccusative set generally speaking. With that aim in mind, I propose (28) (next page) as a minimal taxonomy of [verb+preposition] structures with the potential to be compared to taxonomy (9) above for non-prepositional constructions. A brief description of the differences between both taxonomies is in order in 2.1 and 2.2 below and, then, in 2.2.1 I focus on the specific case of unaccusative structures denoting movement.

\subsection{The agentive types}

Though the agentive [verb+preposition] structures in taxonomy (28) can of course be subject to a fine-grained characterisation according to verb meaning, the minimal types or classes that can be distinguished are: on the one hand, the type of [verb+preposition] structure featuring a dynamic or activity verb and, on the other hand, the type of [verb+preposition] structure featuring a verb of experience. Structures with verbs like put, or also any prepositional structure allowing for one of the so-called argument 
structure alternations, actually belong within the set of activity verbs (see (6)-(7) above): nevertheless, as observed in Section 1.1, an analysis of those structures is out of the scope of this paper. In fact, the characterisation of the agentive set in taxonomy (28) is not at all the primary issue of the present discussion, and a detailed analysis of the contrasts between the structures found here as opposed to those in the non-prepositional taxonomy (9) above actually deserves a separate study of its own. Having said this, I proceed presently to a brief characterisation of the two above-mentioned agentive types in terms of the features [cause] or [causative], [sentience], [movement], and also of course [+/-animate], with a hint at some of the most relevant contrasts or differences between these structures and their non-prepositional counterparts in taxonomy (9).

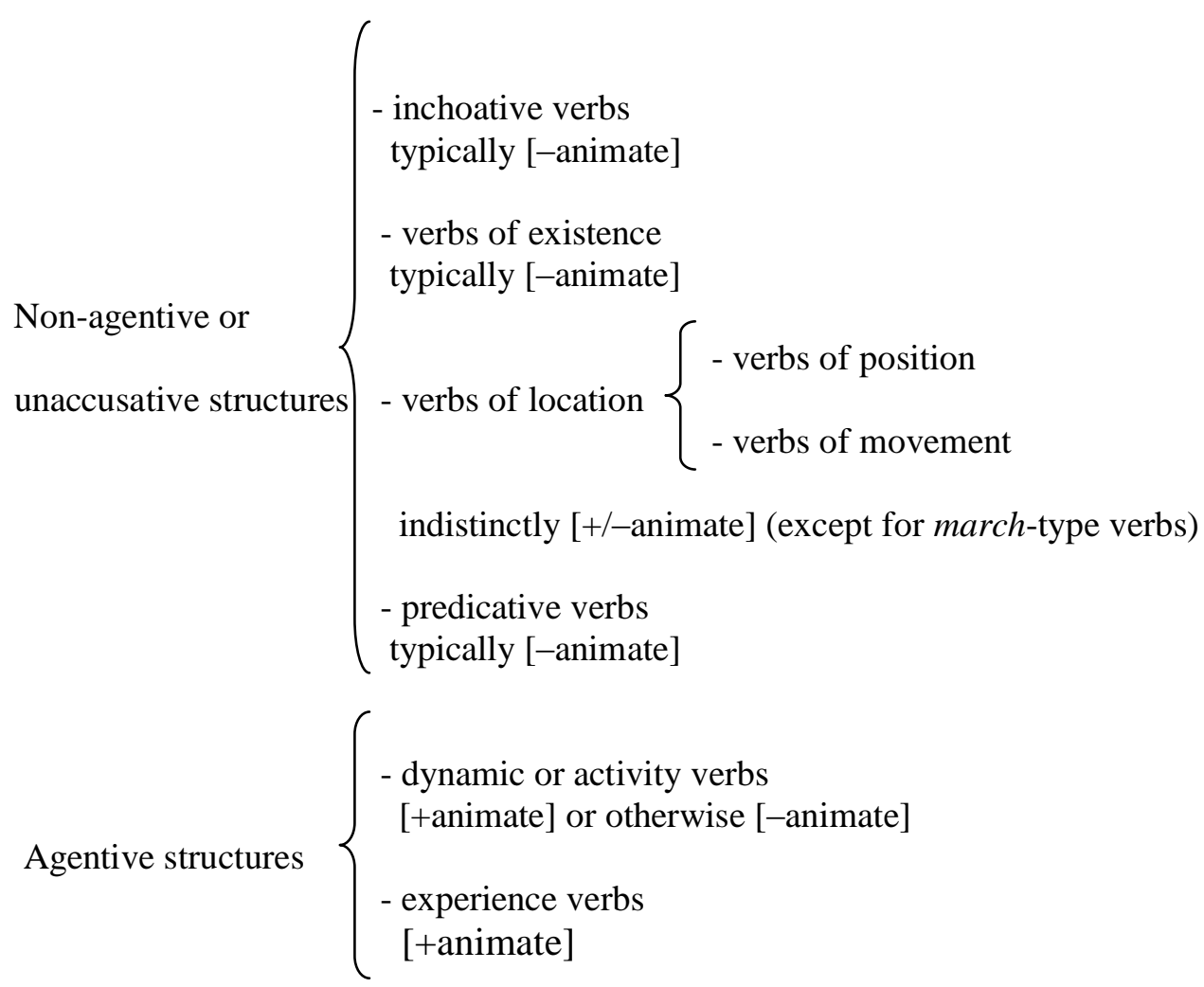

Figure 6

Prepositional sequences with activity or dynamic verbs, as in (29)-(31), must be put in connection with the feature [cause] or [causative], whereas prepositional sequences with experience verbs, as in (32), are, in a logical way, characterised by [sentience]. Further, the same as was the case with non-prepositional structures (see Section 1.2.2 above), [cause] or [causative] subject arguments in the prepositional domain can be either [+animate] or [-animate]: regarding the latter, (30) features natural force subject arguments, whereas the subject arguments in (31) can be identified as instruments. As for the [sentience] arguments in (32), these are typically [+animate]. 
(29) a. John hit at the window

b. Mary couldn't cut at the loaf of bread

c. They are still pounding on the door

(30) a. The rain hit at the window

b. The wind ripped off the wings of the aircraft

(31) a. The saw ripped into the metal

b. Those articles deal with the second hypothesis

c. This bill must provide for the necessary measures to tackle the problem

(32) a. They listened to the news

b. The Government doubts of the efficacy of such measures

c. John is craving for chocolate

Now, at least two aspects appear to differentiate the agentive prepositional domain from the agentive non-prepositional domain as characterised in 1.2.2 above. On the one hand, the extreme scarcity of the class of stimulus/experiencer verbs in the prepositional set, a fact that is acknowledged in Levin (1993:193), and that is the reason why such verbs do not figure in taxonomy (28) above. In Castillo (2010), where a corpus of more than 3,000 [verb+preposition] items is analysed with an aim to study the prepositional passive, only one clear case of object experiencer or stimulus/experiencer prepositional verb is attested: namely, appeal to ${ }^{10}$ As shown in (33), the subject argument of appeal to can be [+animate] or [-animate], though the crucial aspect to highlight is the virtual non-existence of the class in question.

\section{(33) Bright colours / The clown appealed to the children}

The second aspect that, I would like to argue, distinguishes the agentive prepositional set from the agentive non-prepositional set is the nature of the category [+affected] object. Effectively, from the three-fold typology of altered or modified object, displaced object, and effected object that is assumed here (see reference to Anderson (1977) in 1.2.2 above), the category of displaced object must be discarded, since the entity that is depicted as moving in a prepositional structure is typically the one in subject position, and not the one that figures as object. Incidentally, in Castillo (2010), it is argued that to the category of altered or modified object (as in cut at, pound on, rip into,...in (29)(31)), and that of effected object (as in provide for (31c)), should be added the category instrument in the prepositional domain (as in deal with (31b) or also experiment with or play with, for that matter).

After the brief characterisation of agentive [verb+preposition] structures in taxonomy (28) above in terms of [cause] or [causative] and [sentience], with the due reference to the animacy property, it remains to specify whether the feature [movement] can actually be verified to exist for these structures. The relevant question to ask is whether, aside from so-called causatives of manner-of-motion verbs as in The general marched the soldiers to the tents (to be described in 2.2.1 below), there exists a class of movement verbs within the prepositional domain that is genuinely agentive. Now, this 
question actually belongs to work in progress by the author as based on the abovementioned corpus of prepositional passive structures. The core of the analysis is whether a pattern can be found for the relatively small number of [verb+preposition] items denoting movement which allow for the passive construction: since passives arguably demand an agent, then those [verb+preposition] structures that have a passive counterpart could in principle be claimed to be agentive. However, the task is not a straightforward one, since it is necessary to discard first the phenomenon of lexical idiosyncrasy, which happens to have a great impact on the passive phenomenon. The reader is thus referred to work in progress.

\subsection{The unaccusative or non-agentive types}

The core structural type under analysis in this paper is the unaccusative prepositional type. The unaccusative or non-agentive set in taxonomy (28) above differs in two major respects from the corresponding set in the non-prepositional taxonomy (9) presented in Section 1.2. On the one hand, all groups or classes in (28) typically feature a [-animate] subject argument, except for the locative group, whereas it is not just locative structures that allow indistinctly for a [+animate] or a [-animate] subject in the non-prepositional set in (9), but also structures denoting existence and also predicative structures. In the (a) sequences of (34)-(36) below are illustrated typical cases selecting for [-animate] subjects: in (34a) are shown inchoative [verb+preposition] items, and (35a) and (36a) illustrate existential [verb+preposition] items and predicative ones, respectively. ${ }^{11}$ The structures exemplified in (34b), (35b), and (36b), where the surface subject can alternatively be [+animate] or [-animate], are much less frequent in the English lexicon than the structures in (34a), (35a), and (36a).

(34) a. The ship sank down / The cut on her arm might soon close up

b. The child moved around (compare John moved the child around)

(35) a. abound in, admit of, become of, consist of, culminate in, degenerate into, dissolve into, hinge on/upon, occur to, redound to, result in

b. belong to, figure in, gain in

(36) a. answer to, consist in, count against, partake of, reek of, taste of

b. contrast with, differ from

The second major difference between the unaccusative sets in prepositional (28) and non-prepositional (9) centres around the core issue of the discussion in this paper, as is the status of march-type verbs. This is precisely the focus of following 2.2.1.

\subsubsection{Unaccusative [verb+preposition] structures denoting movement}

In order to solve the problem of which of the structural configurations in (27) is the one that corresponds to march-type verbs proper, I focus on the case of a verb like whistle, 
which has actually been put in the literature in connection with an animacy property or condition.

Effectively, a comparison between (37a) and (37b) shows that whistle does not admit for a [-animate] argument like the bullet in Spec,T unless a PP constituent is instantiated. Incidentally, the possibility of a DP like the train in (37b) is justified by the notion of teleological capability, which assimilates the relevant argument to an agentive figure (see also (24) in 1.2.2 above).

(37) a. The bullet whistled *(into the room) / The bullet whistled *(through the window)

b. John / The train whistled

(Bresnan 1994; Folli and Harley 2005: 115; Folli and Harley 2006: 143)

The meaning of whistle is of course not the same if an argument like John (or the train) instead of the bullet figures in Spec,T: basic knowledge of the properties of the referents of these arguments (John/the train on the one hand, and the bullet on the other) suffices to characterise (37a) as movement or motion sequences, as opposed to (37b), which denote an activity. As was the case with the motion verb march in (26) above, the verb whistle in (37a) arguably lacks an external argument or, the same, is an unaccusative verb, which is supported explicitly in e.g. Folli and Harley (2006:143). By contrast, the verb whistle in (37b) belongs to the unergative class, much like the verb march in (25). The verb whistle in (37a) thus belongs to the unaccusative set in taxonomy (28), whereas whistle in (37b) belongs to the dynamic or activity set in taxonomy (9) above.

The aspect that I would like to highlight is that whistle selects for a [+animate] argument only in case the verb phrase is not a prepositional one. In a crucial way, constructions with a verb like march demand a [+animate] subject of motion, irrespective of whether the verb phrase consists of a lone $\mathrm{V}$, or whether it also contains a prepositional projection:

(38) a. The soldiers marched

b. *The pebbles marched

$(=(25 \mathrm{a}))$

(39) a. The soldiers marched to the tents $(=(26 a))$

b. *The pebbles marched to the cliff

That is, both unergative march and unaccusative march appear to impose selectional restrictions on the subject of motion, which would seem to justify a verb phrase configuration where the subject of motion is an argument of the verb: unergative (25a) / (38a) would feature a subject of motion merging in Spec, $v$ and, in a significant way, unaccusative (26a)/(39a) would feature a subject of motion merging in Spec, V. By contrast with unaccusative march, the unaccusative structures with whistle in (37a) appear to impose a [-animate] requirement on the argument that realises the role of subject of motion, which would appear to support a derivational process where the cited subject of motion (the bullet in the examples of (37a)) is an argument of the preposition: 
(40a) would correspond with tree-diagram (27a), and (40b) would be identified with (27b).

(40) a. $\left[{ }_{\nu \mathrm{P}}\left[\mathrm{vp}_{\mathrm{p}}\right.\right.$ Whistle [scthe bullet [ppinto the room $\left.\left.\left.]\right]\right]\right]$

b. ${ }_{{ }_{v P}}\left[\mathrm{vp}_{\mathrm{v}}\right.$ the soldiers [ ${ }_{\mathrm{v}}$ march [pPto the tents]]]]

On the proposed approach, unaccusative march is a two-place predicate that selects for a DP subject of motion, and in addition for a PP constituent, which means that the structure that corresponds to march-type verbs is the one in (40b) above, and not the S(mall)C(lause) structure originally proposed in Hoekstra (1984, 1988). By contrast, whistle is a one-place unaccusative that selects for a complex constituent headed by a preposition, it being therefore the preposition itself that provides for the subject of motion. The precise structural configuration of the complex constituent, which is identified as an SC in the original work of Hoekstra (1988), and also here in (40a), must actually be more articulate than an SC since there seem to be unaccusative [verb+preposition] structures where the preposition selects for two arguments in a Spec position. I deal with such structures in 2.2.2 below and, later, in 3, I propose a plausible structural configuration.

Some reference must be made at this point to roll-type verbs. As will be recalled from Sections 1.2-1.2.2 above, these verbs contrast with march-type verbs in that rolltype verbs appear to demand a [-animate] subject of motion, whereas the subject of motion must be [+animate] with march-type verbs. Now, even if a sequence like (12) above with a [+animate] subject of motion is considered acceptable with roll, roll-type verbs are expected to be analysed like march-type verbs and not like whistle-verbs in that the verb itself, and not the preposition, imposes its own animacy requirements upon the subject of motion (which, incidentally, will be indistinctly [+/-animate] in such a case): this is due to the trivial fact that roll-type verbs behave in the same way independently of the occurrence of a PP constituent in the derivation (that is, they are unaccusatives that typically select for a [-animate] or, in any case, a [+/-animate] subject of motion).

The hypothesis that is explored in this paper consists in the existence of a pattern for the set of prepositional unaccusative structures where it is the preposition that projects the internal argument in case the latter is [-animate]. The hypothesis is based on two observational facts. On the one hand, the majority of unaccusative prepositional structures feature a [-animate] internal argument, whereas this is not the case for unaccusative non-prepositional structures: compare taxonomies (9) and (28) above. On the other hand, from the contrastive analysis implemented in this Section between unaccusative march-type verbs on the one hand and unaccusative whistle-type verbs on the other, it is concluded that the internal argument is supplied by the verb with the former and by the preposition with the latter, it being the case that the former (that is, march-type verbs) select for a [+animate] internal object, whereas the latter (that is, whistle-type verbs) select for a [-animate] internal object. This does not mean that verbs cannot project [-animate] internal arguments: as argued immediately above, such 
appears to be the case with roll-type verbs; even more consistently so, a look at taxonomy (9) leaves no doubt as to the generalised capacity of verbs proper to select for both [+animate] and [-animate] arguments. As to the question whether prepositions can actually project [+animate] arguments, the logical conclusion that seems to be reached is that they are unable to do so, though positive evidence should be needed in this respect. On the present approach, a structure like (41), which is the prepositional variant of (8) above, is thus a structure where the internal argument (many guests) is supplied by the verb. On the present approach, then, the internal argument of arrive is provided by the verb whether the structure is prepositional (as in (41)) or non-prepositional (as in e.g. The guests have arrived). By contrast with this analysis, Hale and Keyser (2002) defend that the internal argument in (41) is supplied by the preposition, whether the latter is present or not. The rejection of the theory of the generalised availability of covert or tacit prepositions ultimately appears to distinguish the present approach from Hale and Keyser's.

\section{(41) Many guests arrived at the party}

In the following Section (2.2.2), I deal with another verb-type that, in a similar fashion to whistle-type verbs, appears to support the correlation between prepositional unaccusative structures on the one hand and [-animate] internal arguments on the other. Meanwhile, I focus for the remainder of the present Section on the so-called causative construction of march-type verbs, despite the fact that these are of course not unaccusative constructions but agentive ones: my purpose is to highlight the animacy requirement that is imposed by march-type verbs, irrespective of their argument structure, and to criticise a work like Folli and Harley (2006), which appears to neglect this basic fact.

Now, Folli and Harley (2006) resort to the notion of cotemporaneity in order to explain the contrasts between the (a) and (b) march-type causatives below, their aim being to refute previous analyses as based on the telic vs. atelic nature of these sequences.

(42) a. The general marched the soldiers to the tents

b. *The lightning marched the soldiers to the tents

(43) a. He waltzed Mary across the room

b. *Anxiety waltzed Mary across the room

While acknowledging the full-fledged critique of the telicity-based approach that is carried out by the authors, and similarly their detailed account of cotemporaneity relations (for which the reader is referred to Folli and Harley (2006) itself), I would like to criticise the notion of cause that is implemented by the authors, which they take from Folli and Harley (2005). On the relevant approach, [cause] or [causative] is taken to entail [-animate]. ${ }^{12}$ As a result, the data in (42)-(43) constitute a problem, which the authors try to solve by arguing that the motion sub-event that is incarnated by the DP 
argument to the right of march or waltz must be coextensive or cotemporaneous with the causative sub-event, that is with the event brought about by the DP argument in Spec, $T$, and this can only be achieved if the entity responsible for the causative subevent is an agent proper, that is a [+animate] entity, and not a cause. The problem with this explanation is that, as the authors actually acknowledge, the grammaticality of a sequence like (44) is unexpected, since the situation is one of cotemporaneity and, nevertheless, the entity responsible for the relevant sub-event (namely, the tide) is [cause], that is [-animate] according to their analysis.

(44) The tide rolled the log up the beach

(Folli and Harley 2006: 151)

In a similar fashion to Folli and Harley (2006), the analysis offered in Zubizarreta and Oh (2007: 145) puts the focus on what is described as the accompany or go-along meaning of the causatives in (42)-(43), which would correspond with the cotemporaneity meaning of Folli and Harley (2006). Interestingly, the authors try to solve the problem posed by (44) by appealing to the notion of direct causation, which (44) would share with the (a) sequences in (42)-(43). They argue that a sequence like (45) below is ungrammatical, as opposed to (44), because the wind cannot directly cause the dog to go into the house. The problem with this approach, as Zubizarreta and Oh actually acknowledge, is that there exist constructions with verbs other than motion ones where the subject cannot be considered to act directly on the object: see (46) below.

(45) *The wind walked the dog into the house

(46) Sam frightened Bob out of the house

(Zubizarreta and Oh 2007: 146)

I would like to argue that both (42)-(43) and (44) are explained in a straightforward way by simply resorting to the selection properties imposed by the verbs upon their argument subjects: thus, march selects for a [+animate] subject, whether it is [cause] or [causative], as in (42), or whether it is not, as in (18)/(25) above, and the same applies to waltz; by contrast, roll takes [-animate] subject arguments, whence (10e) above, and similarly (44). Lastly, the ungrammaticality of (45) is justified on the present approach because a [-animate] subject like the natural force the wind must arguably be selected by a verb denoting force or otherwise change of position, which is not the case with walk.

2.2.2. Unaccusative [verb+preposition] structures denoting movement: the case of twoplace prepositions

From the analysis of the contrast between march-type verbs and a verb of sound emission like whistle as provided in Section 2.2.1 above, it is concluded that the surface 
subject of [verb+preposition] structures that is obligatorily [+animate] is actually an argument of the verb. Now, the approach to [verb+preposition] structures with whistle is extended in the current Section to [verb+preposition] structures with eat, since again the syntax of this predicate appears to be determined in a clear way by the animacy property. Effectively, the difference between (47a) and (47b) appears to support an analysis for eat (or likewise chew) along the lines of the whistle-case in 2.2.1.

(47) a. The sea ate the beach *(away) / The washing machine chewed *(up) the laundry

b. John ate the apple / The cowboy chewed the tough beef

(Folli and Harley 2005: 95, 103, 104)

The hypothesis to defend is for the verb eat (or chew) in (47b) to be a consumption verb proper, that is a dynamic or activity verb within the agentive set in (9) above, with John (or the cowboy) as the external argument, whereas the verb eat in (47a) is an unaccusative verb selecting for a PP constituent that is headed by the particle away. In the latter structure, the internal argument the sea would play the role of subject of motion - much like the bullet in the whistle-structure (37a) above - and the internal argument the beach would arguably realise the role of incremental theme - more precisely, the beach would denote path that is affected in an incremental way. ${ }^{13}$ The verb eat in (47a) is thus analysed here as an unaccusative verb of movement, hence an element within the locative set in taxonomy (28) above. On an approach like Hoekstra (1988), both the whistle-structure (37a) and the eat-structure (47a) would be directional resultatives: more specifically, (37a) would be identified as a bare resultative since the external argument of the preposition eventually moves into surface position; as for (47a), it would be a non-subcategorised-DP resultative on the present approach, since an argument like the beach is not selected by the verb but by the preposition.

At this point I would like to observe that the analysis of (47a) implemented in Folli and Harley (2005) and, similarly, Folli and Harley (2007: 209-212) does not seem to be completely satisfactory. On their approach, the constituents the beach and away make up an S(mall)C(lause) much as in Hoekstra (1984, 1988), or also in Kayne (1985), an idea that the present discussion basically agrees with. However, the authors pretend to resolve the contrast between (47a) and (47b) simply by postulating a flavoured- $v$ approach, which consists in that the type of little $v$ that selects for [-animate] external arguments, which is labelled $v_{\text {cause }}$ on their approach, happens to select for the abovementioned SC, whereas the little $v$ that projects [+animate] external arguments (socalled $v_{\mathrm{do}}$ on their analysis) does not take SC constituents as objects. The configuration that they propose for (47a), which is roughly as in (48), seems therefore to neglect the crucial fact that a constituent like the sea must also be projected by the preposition, which fact is proven by the grammaticality facts in (49)-(50).

(48) $\left[{ }_{v \mathrm{P}}\right.$ the sea $\left[{ }_{\nu}\right.$ ate $\left[{ }_{\mathrm{sc}}[\right.$ the beach][away $\left.\left.\left.]\right]\right]\right]$

(49) ??The sea ate the beach (unless figuratively)

(50) ??John ate the apple away 
Effectively, a sequence like (49) appears to be natural only in a figurative or metaphorical sense, much as (23) above. As was argued in Section 1.2.2 above, natural forces are available as agent or agent-like arguments in non-prepositional structures, though subject to the condition that the relevant verbs be ones denoting force or violence in an unambiguous way (e.g. destroy, devastate, hit, ruin,...), or otherwise the change of position of an object (bend, close, open, ...). For (49) to be a case of figurative or metaphorical use of eat, and not a genuine agentive structure with the sea as the external argument, appears to be supported by the fact that it cannot be used as an optional transitive verb (or an unergative) with a [-animate] argument in subject position: note the contrast between (51a) and (51b) below.

(51) a. John is eating / John ate at 8 yesterday

b. *The sea is eating / *The sea ate at 8 yesterday

In addition to (49)/(51b), a sequence like (50) supports the idea that it is the preposition (or particle) away that selects for a [-animate] argument in the subject position of eat. On the approach defended here, then, both the sea and the beach are arguments of the preposition (or particle) away. In 3 below I suggest a plausible structural configuration for unaccusative [verb+preposition] sequences that is in accordance with the capacity of prepositions to project up to two Spec positions.

\section{Proposed structural configuration}

From the discussion in Section 2.2.1 above it was concluded that the original S(mall)C(lause) configuration proposed by Hoekstra (1988) corresponds only to unaccusative [verb+preposition] structures with a [-animate] surface subject, since unaccusative [verb+preposition] structures with a [+animate] subject are ones where the verb and not the preposition supplies the relevant surface subject, which is of course an internal argument. Thus, the tree-diagram in (27b) above would correspond with the sequence in (52), and (27a) would represent the merge of constituents in a sequence like (53). Nevertheless, the derivation of an unaccusative structure like (54), as discussed in 2.2.2, demands more space than the unaccusative in (53), since the preposition in (54) must arguably supply for two internal arguments in a Spec position.

(52) The soldiers marched to the tents / John flew to the airport (=(1) above)

(53) The bullet whistled into the room

(54) The sea ate the beach away

Now, I propose to replace the SC construct in Hoekstra (1988), and even more precisely the minimalist $v$-P configuration of Hale and Keyser (2002), which is assumed in current works like Folli and Harley (2005, 2006), Harley (2007), or den Dikken (2009), with a configuration where the preposition can unambiguously project two Spec 
positions. The configuration proposed here arguably has the form of a $p \mathrm{P}$-shell structure acting as complement of the verb. ${ }^{14} \mathrm{As}$ is well known, the availability of $p \mathrm{P}$-shell configurations has been independently argued for in the literature: for instance, Matsubara (2000) uses the relevant mechanism to analyse PP constituents in subject position, and Abels (2003) discusses the existence of $p \mathrm{P}$-shells in connection with preposition-stranding.

As a matter of fact, Hale and Keyser (2002: 228ff.) truly acknowledge the ability of particles to project specifier positions. However, their analysis of verb-particle combinations is centred upon a structural type where only one internal object can be claimed to occur (as in She put [her saddle] up on the fence) and they argue that the particle, which is distinguished on their approach from the category of ordinary preposition, plays the role of mediator between the latter (the preposition) and the internal object. Since the core of the analysis proposed here for a sequence like (51) consists in the projection of two arguments of the preposition or particle (see at the end of the Section), then the two analyses are not actually comparable in this respect. ${ }^{15}$

All in all, on the present approach, (53) would be represented as in (55a) and, for its part, (55b) would correspond to (54).

(55) a. $\quad v \mathrm{P}$

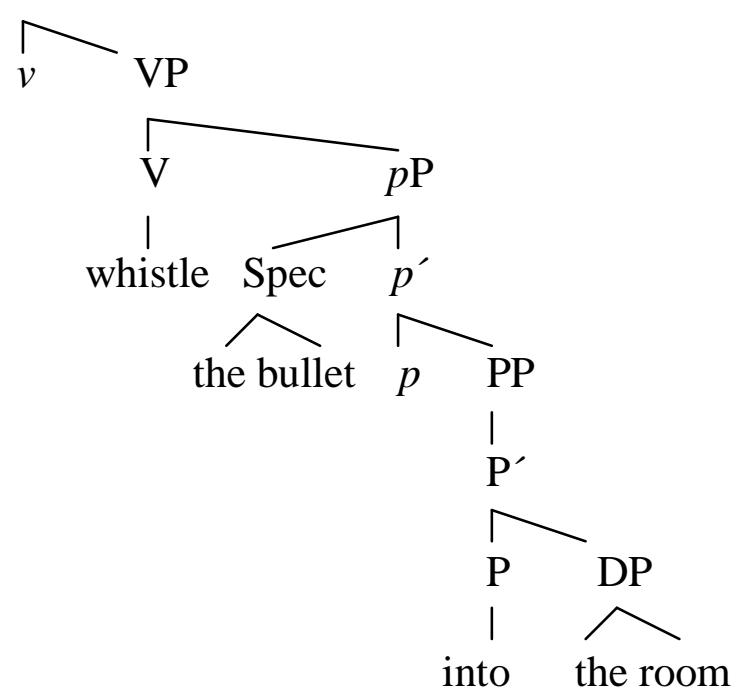

Figure 7

The thematic relations depicted in (55a) and (55b) appear to be in accord with Baker's (1988) principle of Uniformity of Theta-role Assignment Hypothesis or UTAH, since the arguments the bullet and the sea would be both subjects of motion, and they would both figure in the same Spec, $p$ position. As for an argument like the beach in (54), which was characterised in 2.2.2 above as an incremental theme, it would merge initially in the derivation in a Spec position (concretely, in Spec,P) and would thus be identified as a kind of subject, though it is an object in relation to the sea. 
(55) b. $\quad v \mathrm{P}$

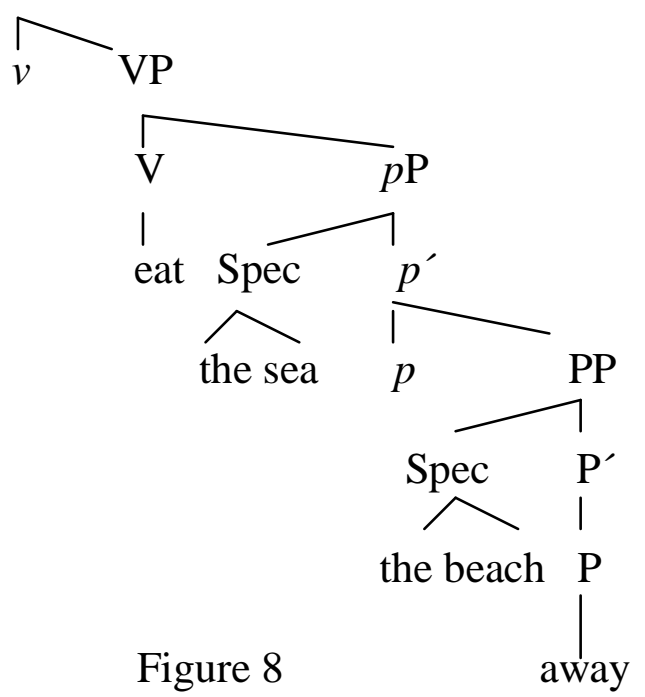

The process of feature-checking that applies in $(55 \mathrm{a}, \mathrm{b})$ would be as follows. Both arguments of $p$ (the bullet and the sea, respectively) are attracted into Spec, T, where nominative Case is licensed, in addition to the licensing of the EPP feature on T. As for the Case-feature on the beach in (55b), the relevant argument would raise into a Spec position of $p$ and would check the corresponding feature there against $\mathrm{V}$, in ECM fashion, just as is assumed for standard or non-prepositional ECM structures like John considers [the child] intelligent or John wants [Mary] to attend the meeting. See (56).

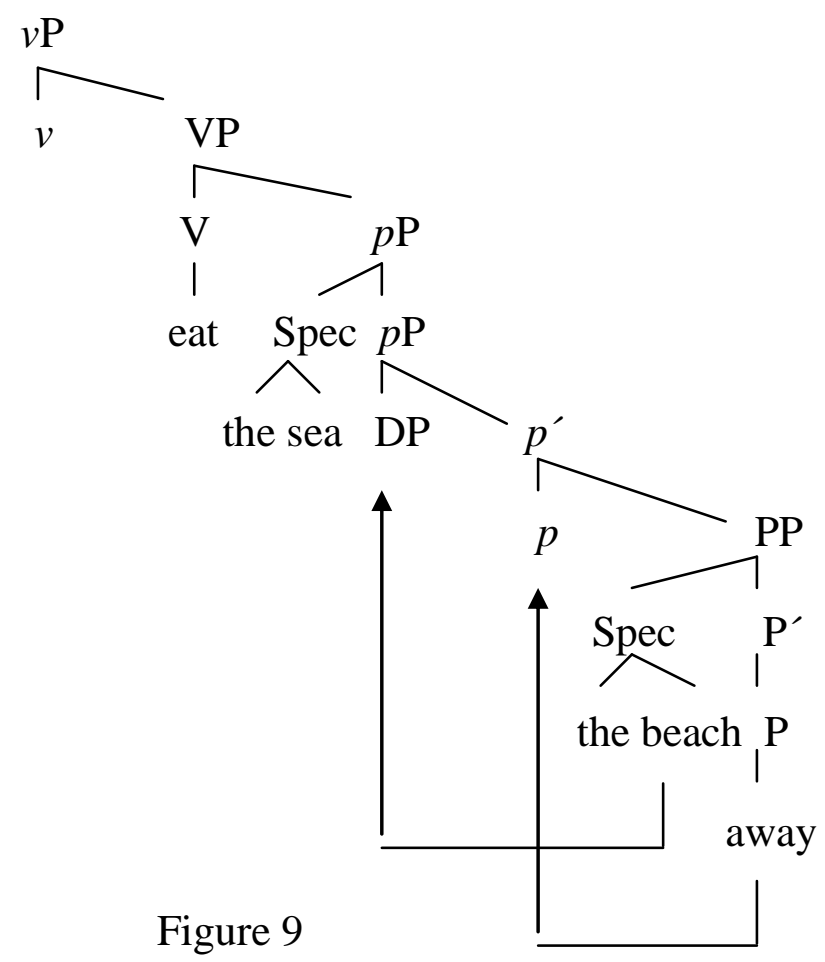


It is of course the case that a sequence like (54) above lends itself to an analysis from the perspective of verb-particle constructions alone, a topic that has been massively researched in the literature from manifold viewpoints. I must insist, however, that the present discussion is exclusively interested in the ability of inherently locative elements (so-called prepositions, whether transitive or intransitive) to behave as predicates and project either one or two Spec positions. Though this paper does not deal then in any way with the issue of the differences in Case-checking between a V-DP-P sequence like e.g. eat the beach away vs. a V-P-DP sequence like eat away the beach, it is expected that future research can prove that a $p$ P-shell-like derivation along the lines of $(55) /(56)$ is suitable for an understanding or an explanation of the relevant phenomenon.

\section{Summary of the approach}

The aim of the paper has been to argue that the internal argument (or surface subject) of unaccusative [verb+preposition] structures is projected by the preposition whenever the latter is [-animate]. The hypothesis is based on two observational facts. On the one hand, the majority of unaccusative prepositional structures features a [-animate] internal argument, as opposed to their non-prepositional counterparts, which generally speaking allow for both [+animate] and [-animate] objects. On the other hand, a principled comparison between (unaccusative) march-type verbs on one side and movement structures with (unaccusative) whistle or (unaccusative) eat on the other gives evidence that it is the verb in the first case that supplies the internal argument, but not so in structures with whistle, or eat: in these, the preposition is in charge of the relevant task.

Assuming then a taxonomy like (28) above for unaccusative [verb+preposition] structures, it has been argued that the preposition projects the relevant internal argument in: inchoative structures, existential structures, predicative structures, and additionally locative structures with a [-animate] internal argument; on the other hand, the verb projects the internal argument in: locative structures with a [+animate] internal argument, among which figure march-sequences in an obligatory way.

Two seminal studies on the ability of prepositions to project subjects or Spec positions have been used, namely Hoekstra (1988) and Hale and Keyser (2002). The reason why the present discussion has focused on structures with agentive vs. unaccusative whistle or eat in order to clarify the case of movement sequences generally speaking is because these predicates have actually been chosen for analysis in works in the current literature like Folli and Harley (2005, 2006), Harley (2007), or Zubizarreta and Oh (2007). A comprehensive search through the set of English [verb+preposition] structures is arguably expected to provide us with the full range of cases where the occurrence of a preposition correlates with the occurrence of a [-animate] subject in surface position.

Finally, a $p \mathrm{P}$-shell configuration has been proposed to match the structures under analysis, since in it the preposition can unambiguously project up to two Spec positions. 


\section{Notes}

1. As is well known, there exists an immense body of work on verb-particle constructions in English, both in the traditional literature and in the generative literature. Most studies can be said to be sensitive to either the SC approach of Kayne (1985), or to a complex-predicate approach, which highlights the fact that the verb and the particle make up a lexico-semantic and syntactic unit (see Farrell (2005) for a broad revision of either view).

2. Regarding the literature on prepositions and theta-roles, it is widely known that classical works like Jackendoff (1972, 1990), Talmy (1975), or Gruber (1976) relate directional prepositions to the category path, and locative prepositions to the category place. As for AP constituents, it is interesting to observe that recent works like Rappaport and Levin (2001) highlight their potential for the expression of directional meaning as entailing result. See the example in (i), taken from Rappaport and Levin (2001:770).

(i) He followed Lassie free of his captors

3. Specifically, den Dikken (2009) uses the set of Dutch prepositions (which includes both prepositions and postpositions) in order to analyse directional resultatives as structures with an event-structural operator in the form of a light verb $v$, and a lexical verb that can either be the spell-out of the $v$ operator, or otherwise merge in the derivation as an adjunct of the latter. The light verb is chosen from a set of five - go, get, be, cause, and do - though the discussion focuses principally on $g o$ and get elements.

4. For example, the temporal meaning of prepositions must be put in connection with an original locative or spatial meaning (ia), and even so-called dummy prepositions can be analysed as deviations from an element with an original interpretation of location (ib).

(i) a. drive [for two hours] / eat an apple [in two minutes]

b. the arrest [of John]

5. Specifically, Dowty (1991: 572) proposes a paradigm of proto-agent roles as in (i) below:

(i) a. volitional involvement in the event or state

b. sentience (and/or perception)

c. causing an event or change of state in another participant

d. movement (relative to the position of another participant)

e. exists independently of the event named by the verb

6. Further, Anderson's category of effected objects (iii) could perhaps be made to correspond within the unaccusative domain with verbs of existence: see (10b) in the main text.

7. Incidentally, the reader is referred to the paradigm of agent proto-arguments of Dowty (1991) for a characterisation of the features [cause], [movement], or [sentience]. See also note 5 above.

8. Incidentally, Levin (1993:79 ff.) includes other values exhibited by [-animate] arguments in subject position that could potentially be subsumed under those cited in the main text: for instance, abstract cause (ia) could be identified with instrument, and time (ib), or container (ic) could be analysed as metaphorical or figurative extensions of [+animate] arguments proper.

(i) a. The letter established his innocence

b. 1492 saw the beginning of a new era

c. The paper incorporates the new results

9. The verbs exemplified in (13)-(16) in the text belong therefore within (21).

10. The reader is referred to Castillo (2010) for a criticism of Levin's (1993) characterisation of items like grate on or jar on as stimulus/experiencer ones. Instead, those 
elements are arguably best located within the dynamic class. All in all, however, the fact remains that the class of stimulus/experiencer verbs is extremely scarce.

11. It is important to observe that some of the [verb+preposition] elements illustrated in (35a) and (36a) actually have an agentive or unergative counterpart which is irrelevant for the discussion at this moment. For instance, the item answer to in (36a) has the unaccusative meaning of 'correspond to, relate to' (The car answers to that description), and not the agentive interpretation relative to an act of communication (as in He answered to the call/to their demands).

12. Compare with our approach in Section 1.2.2 above.

13. As is well known, the notion of incremental theme is closely related to telicity or event boundedness, and it incidentally figures in the paradigm of object properties proposed by Dowty (1991:572).

14. I would like to observe that works like Folli and Harley $(2005,2006)$, Harley (2007), or den Dikken (2009) specifically implement a $v$-SC structure where the SC constituent is immediately below the light verb $v$ and there is no VP in between the two (see also (48) above). This, however, does not affect in any way the $p \mathrm{P}$ construct advocated in the paper.

15. Also, it must be observed that the full-fledged approach to Dutch prepositional and postpositional linear orders of den Dikken (2009), which is a major introduction to an overall research programme, treats particles as optional constituents acting as mediators between the subject of the SC (that is, the internal object) and the predicate of the SC as headed by the preposition. Therefore, den Dikken (2009) does not deal with structures featuring just one particle, as in (54), either.

\section{References}

Abels, Klaus (2003): “*[P Clitic]! -Why?.” Proceedings of Formal Description of Slavic Languages 4, Potsdam, Germany.

Anderson, Stephen (1977): "Comments on the paper by Wasow (The role of the theme in lexical rules)." In P. Culicover et al., eds., Formal Syntax. New York: Academic Press, 361377.

Baker, Mark (1988): Incorporation. Chicago: The University of Chicago Press.

Bresnan, Joan (1994): "Linear order vs. syntactic rank: Evidence from weak crossover." CLS 30, Part I: Papers from the Main Session. Chicago: Chicago Linguistic Society: 57-89.

Broccias, Cristiano (2003): The English Change Network. Berlin: Mouton de Gruyter.

Castillo, Concha (2010): "The class of prepositional passivisable verbs in English." Acta Linguistica Hafniensia 42: 143-174.

Chomsky, Noam (1995): The Minimalist Program. Cambridge, Mass.: MIT Press. (2000): "Minimalist inquiries: The framework." In R. Martin et al., eds., Step by Step: Essays on Minimalist Syntax in Honor of Howard Lasnik. Cambridge, Mass.: MIT Press, 89-155.

_ (2001): "Derivation by phase." In M. Kenstowicz, ed., Ken Hale: A Life in Language. Cambridge, Mass.: MIT Press, 1-52.

Davis, Anthony R. and Jean-Pierre Koenig (2000): "Linking as constraints on word classes in a hierarchical lexicon." Language 76: 56-91.

den Dikken, Marcel (1995): Particles: On the Syntax of Verb-Particle, Triadic, and Causative Constructions. New York and Oxford: Oxford University Press. 
(2006): "On the functional structure of locative and directional PPs." Ms., CUNY Graduate Center.

(2009): "Directions from the Get-Go: On the syntax of manner-of-motion verbs in directional constructions", Ms., CUNY Graduate Center.

Dowty, David (1991): “Thematic proto-roles and argument selection." Language 67: 547-619.

Emonds, Joseph (1972): "Evidence that indirect object movement is a structure-preserving rule." Foundations of Language 8: 546-561.

Farrell, Patrick (2005): "English verb-particle constructions: Constituency and order." Language 81: 96-137.

Folli, Raffaella and Heidi Harley (2005): "Flavors of $v$ : Consuming results in Italian and English.” In P. Kempchinsky and R. Slabakova, eds., Aspectual Inquiries. Dordrecht: Springer, 95-120.

_ (2006): "On the licensing of causatives of directed motion: Waltzing Matilda all over." Studia Linguistica 60: 121-155.

- (2007): "Causation, obligation and argument structure: On the nature of little v." Linguistic Inquiry 38: 197-238.

Gruber, Jeffrey (1976): Lexical Structures in Syntax and Semantics. Amsterdam: North Holland.

Hale, Kenneth and Samuel J. Keyser (1993): "On argument structure and the lexical expression of syntactic relations." In K. Hale and S.J. Keyser, eds., The View from Building 20. Cambridge, Mass.: MIT Press,: 53-104.

- (2002): Prolegomenon to a Theory of Argument Structure. Cambridge, Mass.: MIT Press.

Harley, Heidi (2007): “The bipartite structure of verbs cross-linguistically, or why Mary can't exhibit John her paintings." Talk at the Abralin Congress in Belo Horizonte, Brazil.

Hoekstra, Teun (1984): Transitivity. Grammatical Relations in Government-Binding Theory. Dordrecht: Foris.

Hoekstra, Teun (1988): "Small clause results." Lingua 74: 101-139.

- (1992): “Aspect and Theta-Theory.” In I. Roca, ed., Thematic Structure. Its Role in Grammar. Berlin: Mouton, 145-176.

(1999): “Auxiliary selection in Dutch.” Natural Language and Linguistic Theory 17 : 67-84.

Hoekstra, Teun and René Mulder (1990): "Unergatives as copular verbs." The Linguistic Review 7: 1-79.

Jackendoff, Ray (1972): Semantic Interpretation in Generative Grammar. Cambridge, Mass.: MIT Press.

(1990): Semantic Structures. Cambridge, Mass.: MIT Press.

Kayne, Richard (1985): "Principles of particle constructions." In J. Guéron et al., eds., Grammatical Representation. Dordrecht : Foris 101-140.

Koenig, Jean-Pierre and Anthony Davis (2001): "Sublexical modality and the structure of lexical semantic representations." Linguistics and Philosophy 24: 71-124.

Koopman, Hilda (2000): "Prepositions, postpositions, circumpositions and particles: The structure of Dutch PPs." In H. Koopman, ed., The Syntax of Specifiers and Heads. London: Routledge, 204-260.

Levin, Beth (1993): English Verb Classes and Alternations: A Preliminary Analysis. Chicago and London: The University of Chicago Press.

Levin, Beth and Malka Rappaport Hovav (1005): Unaccusativity: At the Syntax-Lexical Semantics Interface. Cambridge, Mass.: MIT Press,. 
(2005): Argument Realization. Cambridge, Mass.: MIT Press.

Matsubara, Fuminori (2000): “ $p *$ P phases.” Linguistic Analysis 30: 127-161.

Rappaport Hovav, Malka and Beth Levin (2001): "An event structure account of English resultatives." Language 77: 766-797.

Simpson, Jane. (1983): "Resultatives.” In L. Levin et al., eds., Papers in Lexical-Functional Grammar. Bloomington: Indiana University Linguistics Club, 143-157.

Stowell, Tim (1981): Origins of Phrase Structure. Ph.D. dissertation, MIT.

Talmy, Leonard (1975): "Semantics and syntax of motion." In J.P. Kimball, ed., Syntax and Semantics. New York: Academic Press, 181-238.

Zubizarreta, María Luisa and Eunjeong Oh (2007): On the Syntactic Composition of Manner and Motion. Cambridge, Mass.: MIT Press. 